University of Wollongong

Research Online

Faculty of Business - Papers (Archive)

Faculty of Business and Law

2005

Foster carers in New South Wales: profile and projections based on ABS

Census data

Peter Siminski

University of Wollongong, siminski@uow.edu.au

Jenny Chalmers

RMIT University

Marilyn McHugh

University of New South Wales

Follow this and additional works at: https://ro.uow.edu.au/buspapers

Part of the Business Commons

Research Online is the open access institutional repository for the University of Wollongong. For further information contact the UOW Library: research-pubs@uow.edu.au 


\title{
Foster carers in New South Wales: profile and projections based on ABS Census data
}

\begin{abstract}
Administrative data on foster carers in New South Wales (NSW) are sadly lacking. Based on research commissioned by the NSW Department of Community Services, this paper uses the Australian Bureau of Statistics Census of Population and Housing and other data to provide up to date information on the characteristics of foster carers and the demographic trends that are influencing their numbers. Census data indicate that foster carer families are most likely to contain women aged 35-54 years, not in the labour force. Couples account for two thirds of all foster carers, with the majority of those couples also caring for birth children. While single parents account for less than one-fifth of all foster carers, they are more likely to foster than couples, either with or without birth children. Higher rates of fostering were found in relatively disadvantaged areas. Projected increases in female labour force participation are expected to contribute to a decline (or to slower growth) in the number of foster carers over the next decade. However, projected increases in sole parent families and couples without children are expected to have the opposite effect. The relative magnitude of these effects was not ascertained.
\end{abstract}

\section{Keywords}

abs, data, profile, foster, wales, carers, census, projections, south

Disciplines

Business

\section{Publication Details}

Siminski, P., Chalmers, J. \& McHugh, M. (2005). Foster carers in New South Wales: profile and projections based on ABS Census data. Children Australia, 30 (3), 17-24. 


\title{
Foster carers in New South Wales
}

\section{Profile and projections based on ABS Census data}

\author{
Peter Siminski, Jenny Chalmers and Marilyn McHugh
}

\author{
Administrative data on foster carers in New South Wales \\ (NSW) are sadly lacking. Based on research \\ commissioned by the NSW Department of Commmity \\ Services, this paper uses the Australian Bureau of \\ Statistics Census of Population and Housing and other \\ data to provide up-to-date information on the \\ characteristics of foster carers and the demographic \\ wends that are influencing their numbers. Census data \\ indicate that foster carer families are most likely to \\ contain women aged 35-54 years, not in the labour force. \\ Couples account for two-thirds of all foster carers, with \\ the majority of those couples also caring for birth \\ children. While single parents account for less than one- \\ fifth of all foster carers, they are more likely to foster \\ than couples, either with or without birth children. \\ Higher rates of fostering were found in relatively \\ disadvantaged areas. Projected increases in female \\ labour force participation are expected to contribute 10 a \\ decline (or to slower growth) in the number of foster \\ carers over the next decade. However, projected \\ increases in sole parent families and couples without \\ children are expected to have the opposite effect. The \\ relative magnitude of these effects was not ascertained.
}

\begin{abstract}
Children and young people at risk of abuse or neglect in their parental home may require placements (short or extended) in home-based care with foster carers' ${ }^{\prime}$. All State and Territory governments in Australia administer foster care programs. Foster care services are also provided by the non-government sector. A number of recent Australian reports highlight that the provision of home-based care is under considerable stress due to the difficulties of recruiting and retaining carers (Barber 2001; CAFWAA 2002; Carter 2002; DHS 2003, McHugh 2003; Barber \& Delfabbro 2004).
\end{abstract}

Crucial to any attempts to relieve that stress is an understanding of the characteristics of foster carers, and the demographic trends that are influencing their numbers.

Quantitative data about the characteristics of foster carers is sparse. Most jurisdictions in Australia, including that of New South Wales (McHugh, McNab, Smyth, Chalmers, Siminski \& Saunders 2004a; NSW CSC 2000), do not keep adequate administrative data on foster carers. Some sample surveys have been conducted collecting detailed information on foster carers (Gain, Ross \& Fogg 1987; McHugh, et al 2004a).

This study represents the first attempt in NSW to utilise census data to categorise foster carers in terms of their demographic characteristics. Data from the 2001 Census of Population and Housing conducted by the Australian Bureau of Statistics (ABS) are used to show where foster carers in New South $W$ ales reside and describe foster mothers in terms of their family types, age and labour force status. The impact of future demographic change on the pool of foster carers is also examined.

This paper is based on research commissioned in 2003 by the NSW Department of Community Services (DoCS) to examine the current and projected availability of foster carers. The study included an analysis of Census data, a postal survey of DoCS carers, and focus groups with DoCS carers and Departmental workers (McHugh, et al 2004a; $2004 \mathrm{~b}$ ). Whilst the focus here is on the analysis of the Census data, occasional reference is also made to results

\footnotetext{
1 Some of the factors associated with children at risk of abuse or neglect are that parents may be unable to care due to mental health or drug and alcohol problems or parents may be ill or incarcerated. 
from the survey, described in this paper as the McHugh survey.

\section{METHODS}

The purpose of this analysis is two-fold. We identify the family types; in terms of demographic characteristics of foster mothers, in which foster children are most likely to be found. We also calculate the proportions of each family type in the NSW population with foster children, using this as a guide to the tendency for each family type to take on foster care. The results are based on special tabulations of Census data, purchased by the NSW Department of Community Services from the ABS. ${ }^{2}$ The most recent Census was held on August 7, 2001. Foster families were identilied where one or more members of the family were reported as foster children. ${ }^{3}$ Figure I shows an example of how this would be entered on the household form.

\section{Figure 1}

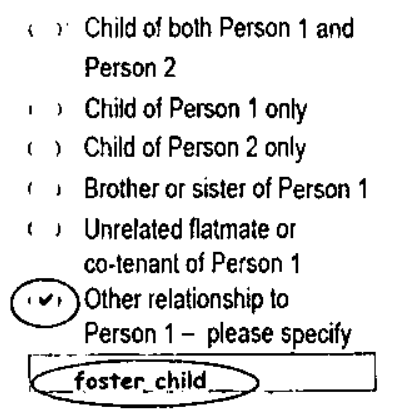

The Census data may underestimate the number of foster families at a point in time for at least three reasons:

- Not all respondents with foster children may actually write 'foster child' or 'foster' under 'other relationship' on the census form. The respondent may simply tick

\footnotetext{
2 As such. simple cross-tabulations are the only form of analysis presented here. Multiple regression techniques could be used to ascertain which characteristics have the strongest independent association with fostering.

${ }^{3}$ A family is defined by the ABS as two or more persons, one of whom is at least 15 years of age, who are related by blood, marriage (registered or de faclo), adoption, step or fostering, and who are usually resident in the same household. Non-related persons living in the same houschold are not counted as family members (unless under 15 years of age). Of people listed as temporarily absent, spouse(s) and family children are used in coding a family type variable. However, variables indicating the presence of foster children and the presence of birll children were based only on those who were present on Census night. This is problematic for an analysis of foster caring by family lype. There is no apparent way to correct for this discrepancy. The numbers affected appear to be small .(for example, two per cent of 'couples with children' are coded as having neither foster children nor birth children).
}

'child of Person 1', since 'child' does not necessarily moan 'biological child".

- The Census data only identifies those foster children staying with their foster family on August 7, 2001 (census night). The details of foster children who stayed somewhere else that night are recorded on the Census form, but the ABS does not make such data available.

- The 'other relationship' option refers only to 'other relationship to Person ' 1 '. Since the Census data is collected on a household basis, rather than by family, it is possible that the foster parent is not Person 1, but one of the other household members. It is unclear how the foster child would be listed in such a situation.

A possible offsetting factor is that some kin/relative carers may be enumerated in these data. ${ }^{4} \mathrm{Wc}$ assume that most children in kin/relative care would be excluded from these data, since their relationship would probably be recorded as 'grandchild' or whatcver the family relationship may be, rather than 'foster child' (Figure 1). In New South Wales, the majority (61 per cent) of children in home-based care was in kin/relative care, while the remainder were in foster care ( 39 per cent) (at June 30, 2001) (AlHW 2002). The combined effect of these factors is impossible to quantify. The limitations of the data need to be kept in mind.

The McHugh et al. (2004a) carer survey found that women were identified as primary carers in 92 per cent of couple foster families. Of single carers in this survey, 87 per cent were female. Therefore, women were the primary carers in approximately 90 per cent of foster families. Given the predominance of women as primary carers and space limitations, the analysis of Census data focuses on the characteristics of female carers.

\section{FOSTERING RATES}

The proportions of foster mothers with certain demographic characteristics (age, family type, labour force status, region) are described. More attention is paid to 'fostering rates', defined as the number of families with foster children per 10,000 families with similar characteristics. ${ }^{5}$ The fostering

\footnotetext{
${ }^{4} \mathrm{Kin} /$ relative care is defined as care of children and young people provided by relatives, usually grandparents, but may include family friends (COTA 2003).

5 It is unclear how one would calculate fostering rates for single carers without birth children. It is not appropriate to compare such carcrs to the set of persons living alone, since they are not the only people who would become 'single foster carer families without birth children' if they fosiered a child. Any adult without a spouse or birth children, regardless of their living arrangements, would need to be counted in the denominator. Such a comparison would not seem to produce meaningful results. Thus fostering rates for single people without birth children were not calculated. For related - reasons. single carers without birth children are excluded from the tolal fostering rates across family types.
} 
rate is seen as providing a guide to the likelihood that a particular family will take on foster children.

It is implicitly assumed that the characteristics defining the families are exogenous to fostering. For example, it is assumed that the labour force status of women influences the propensity to foster, not that women change their labour force status in response to the decision to take on a foster child. $^{6}$

In the case of household income, the exogencity assumption is not reasonable and so fostering rates are not presented by income. Carers of fostered children are entitled to a "Care Allowance' from DoCS, and Family Tax Benefit and/or Parenting Payment from the Commonwealth Government Department of Family and Community Services. Sources of income are not identified in the Census data so income excluding carer entitlements cannot be calculated.

\section{Projections}

In order to investigate the possible effect of demographic trends, projections of the number of foster carer families from 2003 (the time of writing the report) to 2013 were compiled. This change is compared to that of other population groups. The projections are based on published ABS projections of the overall population by age and sex (ABS 2003), and of labour force participation rates by age and sex (ABS 1999b). It was planned to also use published projections of changes in living arrangements in the model (ABS 1999a). However, these data were deemed to be inadequate for a number of reasons. The ABS living arrangement projections do not include breakdowns by gender or by state to sufficient detail. They also do not account for cohort effects related to delayed childbirth, which have the potential to affect the results considerably.

It is important to emphasise that projections are not predictions. Projections simply trace out the future implications of a continuation of past trends. The projections assume that there will be no change in the propensity of tamilies with particular demographic characteristics to take on foster children. Many other (non demographic) factors may influence people's decisions to become foster carers. These include changing societal attitudes to foster care. financial incentives, and changes in the demand for foster care. Therefore, the purpose of this analysis is to examine

\footnotetext{
"It is possible that some foster carers leave the labour force in order to take on foster caring duties, thus questioning the exogeneity assumption. There is some evidence from British studies of kin and relative care that the demands of caring have 'forced' kin carers to leave paid employment to provide care for their kin (COTA 2003). To the authors knowledge, there is no Australian evidence that foster carers are forced to give up paid work by care demands.
}

the possible future effects of demographic changes (only) to the pool of foster carers. The projections were based on ABS 'medium' demographic assumptions. ${ }^{7}$ The method used assumes constant propensities over time. Consider the example of women aged 45-54 years, who are not in the labour force. In New South Wales, about 0.3 per cent of such women were foster carers in 2001 , so it is assumed that the same percentage of women with these characteristics will be foster carers in future years. If the number of such women is projected to increase by 8 per cent over the coming 10 years, it is assumed that the number of foster carers with those same characteristics will also increase by 8 per cent. This is a common method of compiling simple projections to examine the possible effect of future demographic changes on the population of interest (Gilcs, Cameron \& Crotty 2003; Tesfaghiorghis 2002).

Historically, Australian women tended to leave work when they married, remained out of the labour force during their child-rearing years, and returned when their children had grown. There was often a second exit initiated by the need to care for older family members. More recent cohorts of women tended to remain in paid work until the birth of the first child, although the tendency to leave work on the birth of the first child has diminished with time. Indeed, mothers from the most recent birth cohorts are more likely than not to return to work after their first child is born (OECD 2002: 47). Explicit in the ABS labour force projections is the continuation of this trend, with women's participation rates projected to increase in all age groups except those aged 1519 years and 65 years and over. The participation rates of women aged 55-59 years are projected to increase the most.

\section{RESULTS}

The data suggest that on Census night, some 1865 families in New South Wales contained at least one foster child. One of every one thousand families had a foster child in their care (fostering rate $=9.8$ per 10,000 families).

\section{FAMILY TYPE, AGE AND EMPLOYMENT STATUS OF FOSTER MOTHERS}

Table 1 shows fostering rates for families in New South Wales by age, family type and employment status of the female. Most foster motheis were aged between 35 and 54 years (7.0 per cent). The fostering rate was highest for

\footnotetext{
7 Specifically. the series is based on ABS (2003) Series B population projections, which adopted 'medium' assumptions of life expectancy, overseas migration and interstate migration and relatively low future fertility. Sensitivity tests were also conducted. adopting the corresponding 'high' and 'low' assumptions, and were reported in McHugh et al. (2004b). In broad terms. the results presented here are not sensitive to these assumptions. Note that only one set of labour force participation projections was used, since it wiss the only set utilised in the ABS (1909) publication.
} 
Table 1: Foster mothers in NSW by family type, age and employment status - 2001

\begin{tabular}{|c|c|c|c|c|c|c|c|c|c|c|}
\hline & \multicolumn{9}{|c|}{ Age of foster mother (years) } & \multirow{3}{*}{$\begin{array}{c}\% \text { of } \\
\text { foster } \\
\text { families }\end{array}$} \\
\hline & $15-24$ & 25.34 & $35-44$ & $45-54$ & $55-64$ & $65-74$ & $75+$ & $\begin{array}{c}\text { Not } \\
\text { present }\end{array}$ & All & \\
\hline Family Type & \multicolumn{9}{|c|}{ Fostering Rate (per 10,000 families) } & \\
\hline Couples - with birth children & 1.6 & 5.4 & 10.2 & 13.9 & 10.2 & 2.5 & 0.0 & 9.1 & 9.6 & 39.8 \\
\hline Couples - without birth children & 0.8 & 5.9 & 26.0 & 21.3 & 7.1 & 1.8 & 0.6 & 4.1 & 8.7 & 27.8 \\
\hline All Couples & 1.1 & 5.6 & 12.2 & 16.5 & 8.0 & 1.9 & 0.5 & 5.5 & 9.2 & 67.6 \\
\hline Singles - with birth children & 0.0 & 8.7 & 18.0 & 22.9 & 22.2 & 5.5 & 3.2 & 3.8 & 12.9 & 17.0 \\
\hline Singles - without birth children & & & & & n.a. & & & & & 15.4 \\
\hline All Singles & & & & & n.a. & & & & & 32.4 \\
\hline \multicolumn{11}{|c|}{ Employment status of female carer } \\
\hline Employed & 0.8 & 3.9 & 9.3 & 10.8 & 6.8 & 2.8 & 13.0 & n.a. & 7.8 & 39.1 \\
\hline Unemployed & $0.0^{\circ}$ & 9.5 & 11.9 & 14.4 & 24.4 & 0.0 & 0.0 & n.a. & 11.1 & 2.9 \\
\hline NILF & 1.3 & 9.4 & 21.9 & 33.0 & 10.0 & 2.3 & 0.8 & n.a. & 12.9 & 56.3 \\
\hline not stated & 0.0 & 0.0 & 10.4 & 31.3 & 22.5 & 0.0 & 0.0 & n.a. & 7.7 & 1.1 \\
\hline not present & & & & n.a & & & & 2.3 & 2.3 & 0.7 \\
\hline All & 0.9 & 6.0 & 13.0 & 17.2 & 9.2 & 2.2 & 1.1 & 2.3 & $9.8^{*}$ & 100.0 \\
\hline$\%$ of foster families & 0.7 & 11.5 & 31.5 & 38.4 & 13.1 & 2.7 & 1.4 & 0.7 & 100.0 & \\
\hline
\end{tabular}

- Excludes single carers without birth children (see footnote 6 ) and single male carers.

women in this age group, peaking at 17.2 per 10,000 families containing women aged $45-54$ years.

Over two-thirds ( 68 per cent) of foster mothers were part of a couple. Two-fifths ( 40 per cent) were part of a couple with birth children, while 28 per cent were part of a couple without birth children. ${ }^{8}$ Seventeen per cent were single carers living with birth children, and 15 per cent were single carers without birth children.

Amongst couple carers, very few of the foster mothers were younger than 25 years or older than 64 years. In contrast, the single female carers were substantially older with nearly 10 per cent being at least 65 years old and less than half falling into the 35 to 54 year age bracket. Foster mothers in couples without birth children were somewhat older than their counterparts with children.

Whilst there was not a large difference in fostering rates between family types, single mothers (with birth children) were more likely to be foster carers than the other family types. However, there were significant differences in the age distributions of the family types. About 64 per cent of

\footnotetext{
${ }^{8}$ For ease of discussion and for the purposes of this paper, the term 'birth children' is used rather than a more cumbersome, though more accurate term such as 'non-foster children'. The majority of these children are birth children. though some may have been adopted or have been other relatives.
}

partnered women with children were in the peak fostering age of 35-54, compared to 52 per cent of sole mothers, and just 25 per cent of partnered women without children (the majority of whom are older). Within this age range, fostering rates are considerably lower amongst couples with children than for the other two family types. Couples with children have a lower "standardised" fostering rate $(8.3$ per 10,000$)$, than couples without children (19.2) or single mothers (12.3).

A side issue of interest is the question of how many of the foster mothers had looked after birth children before taking on foster children. By combining the Census data with the McHugh et al. (2004a) survey of foster carer families, the analysis suggests that about one-third of foster families had not cared for birth children before caring for foster

\footnotetext{
"Standardisation' refers here to a process of re-weighting the data in order to remove the effect of varying age and labour force status distributions between family types. The weights applied here correspond to the overall age and labour force status distribution amongst women in these three family types. Alternative weights can also be used. such as those that correspond to the age and labour force distribution for one particular family type. Under each of these alternative adjustments, couples with children have the lowest standardised fostering rates. However, it should be emphasised that other possible confounding factors, such as age of youngest child and region of residence, are not held constant by this method.
} 
children. "' On the basis of age, it is clear that at least onefith of foster carer families will never have birlh children, seemingly substituting foster children for birth children.

A majority (56.3 per cent) of foster mothers were not in the labour force, though a significant proportion (39.1 per cent) were in paid employment. In comparison, amongst carer couples less than a quarter (23.3 per cent) of foster fathers were not in the labour force, while more than two-thirds (69.3 per cent) were employed.

The fostering rate was highest amongst families containing women out of the labour force, followed by families with women who were unemployed. Fanilies with employed women were considerably less likely to take on foster children. Amongst women in the peak fostering age (45-54 years), the fostering rate was more than three times higher for families with women out of the labour force (33.0), than for families with employed women (10.8).

\section{DOCS REGIONS}

Table 2 summarises the distribution of families with foster children in NSW by each of the DoCS regions. The first column shows that two regions each contained more than 10 per cent of the families - South West Sydney and the Hunter. The next highest proportions of foster carer families were found for Cumberland/Prospect, Nepean, Far North Coast and the Illawarra. These results are partly a function of the relative population sizes of each region.

The second column shows that in most cases, regions outside of Sydney had higher rates of fostering than regions within Sydney. Central West and the Far North Coast were the regions with the highest rates of fostering (18.3 and 17.9 respectively), while the Inner West of Sydney and Northern Sydney had the lowest rates ( 3.4 and 3.9 respectively). The third column shows SEIFA scores (ABS Index of Advantage and Disadvantage 2001) for each area (ABS 2005). A relatively low SEIFA score represents socio-economic disadvantage for that area. The correlation between the SEIFA score and the fostering rate is very high $(-0.82)$, suggesting a strong relationship.

\footnotetext{
${ }^{10}$ The Census data show that over 43 per cent of the foster carer families did not include birth children. Roughly 31 per cent of the female carers in this group were aged less than 45 years. Presuming that they had no birth children (otherwise they would be living with them), this means at least 13 per cent of foster carcr families had only cared for foster children $(0.43 \times 0.31)$. What can we say of the remaining $69 \%$ of families without birth children, who were headed by women aged 45 years or over? The McHugh survey showed that roughly 63 per cent of primary carers aged 45 years or more who were lixing without birth children had never had birth children (unpublished data from McHugh et al., 20(04a). Thus another 19 per cent of foster carer families had not cared for birth childen in the past $(0.43 \times 0.69 \times 0.63)$. In total, an estimated 32 per cent of carer families had only cared for foster children.
}

Table 2: Foster families in NSW by DoCS Region

\begin{tabular}{|c|c|c|c|}
\hline DoCS region ${ }^{a}$ & $\begin{array}{c}\text { Proportion } \\
\text { of families } \\
(\%)\end{array}$ & $\begin{array}{c}\text { Fostering Rate } \\
\text { (per 10,000 } \\
\text { families) }^{\mathrm{b}}\end{array}$ & $\begin{array}{c}\text { SEIFA } 2001 \\
\text { (Advantage/ } \\
\text { Disadvantage) }\end{array}$ \\
\hline Central Coast & 4.9 & 10.3 & 976 \\
\hline Cumberland/Prospect & 7.7 & 8.3 & $1021^{c}$ \\
\hline Inner West & 2.3 & 3.4 & 1058 \\
\hline Nepean & 8.4 & 13.6 & $1025^{\circ}$ \\
\hline Nolthern Sydney & 4.6 & 3.9 & 1156 \\
\hline South East Sydney & 5.7 & 4.7 & 1094 \\
\hline South West Sydney & 12.4 & 10.3 & 965 \\
\hline Central West & 4.9 & 18.3 & 954 \\
\hline Far North Coast & 7.9 & 17.9 & 933 \\
\hline Hunter & 10.7 & 12.4 & 964 \\
\hline Iilawarra & 7.6 & 11.9 & 974 \\
\hline Mid North Coast & 6.6 & 14.5 & 925 \\
\hline New England & 4.3 & 15.2 & 946 \\
\hline Orana/Far West & 3.7 & 13.6 & 934 \\
\hline Riverina/Murray & 4.1 & 10.1 & 955 \\
\hline Southem Highlands & 4.3 & 12.5 & 990 \\
\hline Total & 100.0 & 9.8 & 1015 \\
\hline
\end{tabular}

Notes:

a See McHugh et al. (2004b) for concordance between DoCS regions and standard ABS geographical (ASGC) categories

b Excludes single carers without birh children (see footnole 6).

c The SEIFA score for Cumberland/Prospect has been estimated from available data. The actual SEIFA score is between 1017 and 1025.

d The SEIFA score for Nepean has been estimated from available data. The actual SEIFA score is between 1020 and 1031.

It was hypothesised that this correlation could reflect demographic differences between potential carers in the regions. For example, women might be less likely to be employed in economically disadvantaged areas. To test this hypothesis, adjusted fostering rates were calculated, where the effects of differences in age, labour force status and family type of women were standardised across regions. The correlation between this adjusted rate and SEIFA was virtually identical $(-0.81)$ to that of the unadjusted rate.

\section{PROJECTIONS}

The projections suggest that the number of foster carer families will increase by less than the overall population of adult women. The projections result in an increase in the number of foster carer families by 7.5 per cent between 2003 and 2013. In comparison, the population of women aged over 15 years is projected to increase by 11.0 per cent, while the number of children younger than 15 years is projected to decrease by 5.1 per cent. It is important to note, however, that the projected decrease in the number of children does 
not necessarily imply a decline in the demand for foster care. These results are illustrated in Figure 2.

There is a projected increase in the proportion of foster carer families containing a female aged over 55 years (from 16.5 per cent to 21.1 per cent). However, in 2013, as in 2001, about two-thirds of foster carer families will include women aged 35-54 years (63.6 per cent in 2013, down slightly from 67.3 per cent in 2001). More substantial changes in the composition could of course occur, but under the assumptions that underlie these projections, they will not be driven by changes in the age structure of the female . population, or changes in labour force participation rates of women.

\section{DISCUSSION}

An attempt has been made to identify the basic characteristics of foster carers in New South Wales from Census data. Foster carers are most likely to be women. aged 35-54 years, especially those not in paid work. Of the various family types, single mothers are most likely to foster. Due to their large numbers, however, couples with birth children account for two-fifths of foster carers.

Some of these findings represent significant changes from the survey results reported by Gain et al. (1987). Compared with Gain's 1986 survey results, the Census data indicates that carer families in 2001 were more likely to be single carers ( 32 per cent compared to 14 per cent). Female carers were more likely to be employed ( 39 per cent compared to 31 per cent), and were more likely to be older ( 70 per cent were aged $35-54$ years in 2001 , while 80 per cent werc aged 25-39 years in 1986). The Census results are also broadly consistent with those from the survey conducted by $\mathrm{McHugh}$ et al. (2004a) in 2003.

\section{EMPLOYMENT STATUS}

Contemporary fostering is perceived as both emotionally and physically demanding (UK Health Committee 1998; Allbeury 2003; McHugh et al. 2004a; Barber \& Delfabbro 2004). As a consequence, it is not surprising to find that the primary carers of foster children - women - are relatively unlikely to combine paid work with their caring role. However, the very notion of investigating the labour force status of carers, as done in this paper, is itself only meaningful within a given paradigm of foster care as a predominantly unpaid activity. Professional care models, which are currently being looked at as part of the out-ofhome care reforms, are a direct challenge to this paradigm.

\section{REGIONS}

There is a strong correlation between fostcring rates and regional socio-economic status (SEIFA). This correlation is not explained by regional differences in women's age, employment status and family type. Instead, it is likely that
Figure 2

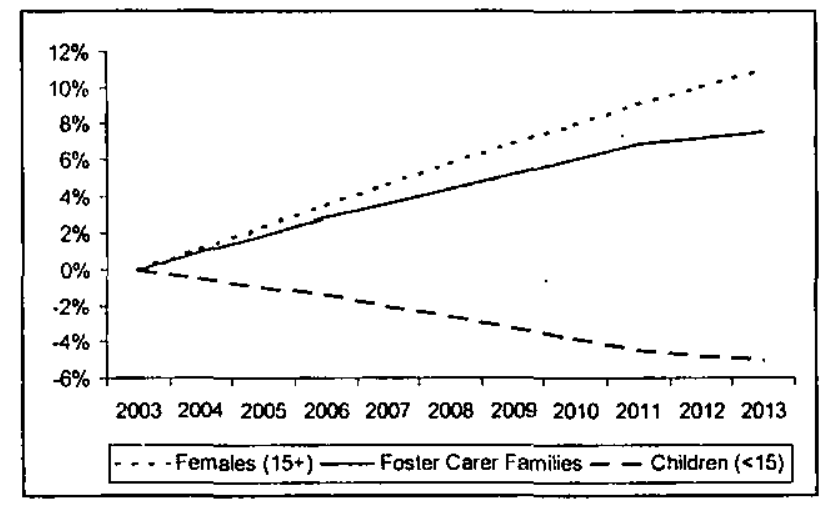

the result is driven by regional differences in the need for carers. Areas of lower socio-economic status have a greater need for foster care. Where possible. DoCS attempts to place foster children in close geographical proximity to their families, and efforts to recruit new foster carers are concentrated in those areas. To paraphrase these results in the terms of economics, regional differences in the numbers of foster carers appear more likcly to be driven by demandside factors. This does not imply that supply-side incentives will not be elfective in increasing the number of foster carers over time.

\section{TRENDS AND PROJECTIONS}

In light of the annual increase (around 10 per cent) in the numbers of children and young people requiring out-ofhome care services (DoCS 2004), the factors that impact on the pool of foster carers is of considerable interest to government. Some reports claim that the pool of foster carers is decreasing (CAFWAA 2002; DHS 2003; NSW CSC 2000). It has been suggested that the increasingly complex needs (eg, challenging behaviours) of children requiring care has led to some difficulty in retaining carers in the system (CAFWAA 2002; DHS 2003; Osborn \& Delfabbro 2005; Sultmann \& Testro 2001).

The proposed introduction by DoCS of intensive fostering services for children and young people with high needs, significant disabilities and large sibling groups (DoCS 2004) may lead to increased remuneration for the specialist carers recruited. As these models are still being finalised by the Department it is too early to speculate as to how new models of care might impact on fostering more generally or the future supply of carers.

Barber and Delfabbro (2004), McHugh (2003) and Barber (2001) have suggested that a number of demographic trends have also impacted negatively on the supply of foster carers. Of the trends discussed by Barber (2001), three are relevant to the present analysis. These are the increase in female labour force participation, the ageing of the population, and 
the increase in sole parent familics, which are discussed in turn below'.

The findings in this paper suggest that future increases in the labour force participation of women will be a small contributing factor to decline (or to slower growtl) in the number of foster carers. The difference between the projected increases of foster carers and that of all adult women is 3.5 percentage points over ten years. Most (3.1 percentage points) of this difference is due to a projected increase in women's labour force participation. If one was to extrapolate these results to earlier years, it is likely that the rising labour force participation of w'omen has been a factor (albeit a relatively small factor) in recent decreases in foster carers.

At face value, the results also suggest that population ageing will not contribute to a decline in the pool of potential foster carers, since the number of women in the main fostering age groups will increase. However, Barber's (2001) argument was that the ageing population will result in more elderly people needing care, thus diminishing the overall number of people with the capacity to foster (see also Barber \& Delfabbro 2004). This suggestion has not been accounted for in the results presented here.

Our results do not support the claim that an increase in sole parent families has contributed to a fall in fostering rates. Single parent families have the highest fostering rates of all family types. However, many foster children come from single parent families (DHS 2003). Thus the increase in prevalence of sole parent families may have increased both fostering rates and the need for fostering. If past trends continue, future increases in sole parent families and couples without children will contribute to slower decline (or faster growth) in the number of foster carers in New South Wales. As mentioned earlier, however, available ABS projections data do not facilitate an investigation of the magnitude of this effect. On the other hand, if the Federal Government's welfare reforms result in a movement of sole parents into the labour force, the projected growth in their numbers will not increase the supply of foster carers.

Barber and Delfabbro (2004) also suggest that industrial deregulation may have had a negative effect on fostering rates. Longer working hours and irregular shifts in service industries may impede women in paid work to take on fostering (ibid: 49-50). Further industrial relations reforms that will weaken minimum working conditions appear imminent. These could thus result in a further negative impact on fostering rates.

\section{FURTHER RESEARCH}

This approach to studying foster carers has much potential for further application, especially given the limitations of existing administrative data. Similar studies could be undertaken for other States and Territories. Analyses of trends over time are also possible.

The analytical components of this paper must be seen as preliminary, as confounding factors were not held constant. Multivariate techniques could be used to find independent associations between fostering and each of the demographic characteristics. However, the quality of these data is somewhat unknown. If the ABS was to include a 'foster child' category for relationship questions in the Census questionnaire, the data quality would probably improve and the resulting analysis would be more reliable.

\section{REFERENCES}

ABS, sec Australian Bureau of Statistics.

AlHW, see Australian lnstitute of Health and Welfare.

Allbeury, B. (2003) Western Australia Foster Care Recruitunent Service (personal communication).

Australian Bureau of Statistics (1999a) Household and Family Projections: Australia 1996 to 2021, ABS Cat. No. 3236.0. ABS.

Austrnlian Bureau of Statistics (1999b) Labour Force Projections: Australia 1999 1o 2016. ABS Cat. No. 6260.0, ABS.

Australian Burcau of Statistics (2003) Population Projections: Australia 2002-2101. ABS Cat. No. 3220.0, ABS.

Australian Bureau of Stalistics (2005) New South Wales in Focus, ABS Cat. No. 1338.1, ABS.

Australian Institute of Health and Welfare (2002) Child Protection Australia 2000-01, Child Welfare Series no. 29, AlHW Cat. No. CWS 16, AlHW, Canberra.

Barber, J.G. (2001) 'The slow demise of foster care in South Australia', Journal of Social Policy, 30(1). pp.1-15.

Barber, J.G. \& Delfabbro, P.H. (2004) Children in Foster Care, Routledge, New York.

CAAFWA, see Child and Family Welfare Association of Australia.

COTA, see Council of the Ageing.

Carter, J. (2002) ... towards better foster care ... reducing the risks, The Children`s Foundation, Melboume.

Child and Family Welfare Association of Australia inc. (2002) A Time to Imest: Policu Document, Child and Family Welfare Association of Australia. Available: http://ww' $\mathbf{w}$ familiesaustralia.org.au

Council of the Ageing 2003, Grandporents raising grandchilden, a report of the project commissioned by the Hon. Larry Anthony, Minister for Children and Youth Affairs, Canberra.

DHS, see Department of Human Services, Victoria.

DoCS, see Department of Community Services NSW.

Department of Community Services (2004) Framevork for the Future of Out of Home Care in NSW, Out of Home Care Directorate, Sydney.

Department of Human Services (2003) Public Parenting: A review of home based care in Victoria, DHS, Melboume.

Gain. L., Ross, E. \& Fogg, S. (1987) The Balancing Act: Foster Care in $N S W^{\prime}$, NCOSS, Sydney.

Giles, L.C., Cameron. I.D. \& Crotty. M. (2003) 'Disability in older Australians: Projections for 2006-2031', Mextical Jommat of Australia, 179(3). pp.130-133.

McHugl, M. (2003) 'Paying for care: The statc of allairs in fostering', paper presented to the 8th AIFS Conference, Steps Forz'ard for Families: Research, Practice and Policy, Melbourne, 12-14 February. 
Mcllugh, M., MeNah, I., Smyth, C.. Chalmers, I.. Siminski, P. \& Saunders, P. (2004a) The A wailubility of Foster Carers, Final Repert. prepared for the NSW Department of Community Services, Social Policy Researcl Centre. University of New South Wales. Sydney.

McHugh. M., McNab, J., Smyth. C., Chalmers, J., Siminski, P. \& Saunders, P. (2004b) The Availabilit' of Foster Carers, Supplementiary Mitcrial, prepared for the NSW Deparment of Community Services. Social Policy Research Centre. University of New South Wales, Sydney.

NSW CSC, see New South Wales Community Services Commission. New South Wales Community Services Conmuission (2000) Substitute Care in NSH': New Dircetions - from Suhstitute to Supported Care. CSC. Sydney.

OECD, see Organisation for Economic Co-operation and Development. Organisation for Economic Co-operation and Development (2002) Babies and Busses: Reconciling work and family life, OECD, Paris.

Osborn, A. \& Delfrabbro, P. (2005) 'Children with high support needs in Australasian out-of-home care: A national comparative study", paper presented to 9th Australian institute of Family Studies Conference, Melbourne. 9-1I February.

Sulumann, C. \& Testro, P. (2001) Directions in ont-of-home care: Challenges and oppormmities, PeakCare Qucensland Inc., Brisbane.

Tesfaghiorghis, H. (2002) 'Projections of the number of Income Support recipients: 2001-2051', Australian Social Policy, 2001-20(12, pp.43-78.

UK Health Conmintee (1998) Second Report: Children Looked Affer by. Local Authorities,

ww'w.parliament.uk/parliamentary_committees/health_committee.cfim

\section{ACKNOWLEDGENENTS}

This paper is based on researcl commissioned in 2003 by the NSW Department of Community Services (DoCS) to examine the current and projected aviliability of foster carers (McHugh. McNab, Smyth. Chalmers. Siminski \& Saunders 2004a: 2004b).

The authors acknowledge the comments provided by DoCS officers. Bruce Bradbury and wo anonymous referees. We are indebted to Bruce Bradbury for suggesting the use of Census data to examine the profile of foster carers at a point in time, and to Peter Saunders for suggesting lise use of ABS population projections as a basis for projecting the numbers of foster carers. We thank Paul Murrin (ABS) for his patient assistance in compiling the Census tabulations.

The authors are responsible for any crrors or omissions. The views expressed in the paper are those of the authors.

\section{(9)}

\section{TOWARDS BETTER OUTCOMES FOR YOUNG PEOPLE LEAYING STATE CARE}

\section{November 2005}

Monash University and the Centre for Excellence in Child and Family Welfare invite you to attend Towards Better Outcomes for Young People Leaving State Care, a oneday policy and research conference to be held at the Caulfield Campus (Melbourne) of Monash University on Tuesday 22 November 2005.

There will be keynote lectures from Professor John Pinkerton (Queen's University, Belfast) and Associate Professor Mike Clare (University of Western Australia) as well as invited speakers and contributed paper sessions. A panel discussion focusing on the implications of the new Victorian Children's Bill is also planned.

Abstracts for papers must be submitted by 21 October 2005.

Further information regarding the conference can be obtained from either:

Dr. Catherine Forbes (Catherine.Forbes@buseco.monash.edu.au or (03) 9905 2471). or

Dr. Philip Mendes (Philip.Mendes@med.monash.edu.au or (03) 9903 1132). 